\title{
A Area do Novo Distrito Federal: Condições de Solo, Clima e Recursos Naturais
}

\author{
Vicente Ferrer Correia Lima \\ e \\ Tomás de Vilanova Monteiro Lopes
}

\begin{abstract}
Despe que surgiu a idéia da mudança da capital do país, pretendeu-se que esta última tôsse localizada longe do litoral. Tôdas as sugestões se referiam, vagamente, ao "interior", sem precisar, entretanto, a região mais indicada.
\end{abstract}

Parece, mesmo, que a princípio não havia preferência por esta ou aquela região, e que seria aceita qualquer uma onde a sede do govêrno estivesse a salvo de perigos idênticos aos que se verificaram por ocasião das invasões de Pernambuco, Bahia e Rio de Janeiro pelos holandeses e franceses. Sendo sobretudo de ordem estratégica os motivos que aconselhavam a mudança da capital, a preocupação dominante era afastar do litoral a sede do govêrno.

Foi sòmente a partir de 1813 que as referências ao «interior» começaram a vir acompanhadas de esclarecimentos que lhe imprimiam um significado mais definido. Hipólito José da Costa Furtado de Mendonça, escrevendo, então no «Correio Brasiliense», preconizava a construção da nova capital junto às cabeceiras do rio São Francisco "numa situação que se pode comparar com a descrição que temos do paraíso terrestre".

Entre as emendas ao projeto de Constituição que as Côrtes de Lisboa estiveram discutindo, em 1821, destacava-se a que recomendava a construção de «uma cidade central no interior do Brasil, para assento da Côrte de Regência, podendo ser na latitude de mais ou menos 15 graus». Essa idéia, que recebeu o vibrante apoio de José Bonifácio de Andrada e Silva, era desenvolvida, pouco depois, num aditamento ao referido projeto. $\mathrm{E}^{\prime}$ ai que a futura capital recebe o nome de Brasilia e tem sua localização prevista entre as nascentes dos rios Paraguai e Amazonas.

Em 1824, os líderes da Confederação do Equador manifestaram a resolução de localizar "num sitio fértil, sadio e que distasse 40 léguas do litoral" a capital da república que pretendiam instituir.

Já por essa época eram invocadas para justificar a mudança da sede do govêrno, além das preocupações da defesa militar, as necessidades da colon:- 
zaçãc e do desenvolvimento econômico. Dentro dessa nova orientação, afirmava um dos jornais da época, o «Universal», de Ouro Prêto.

«Uma importante vantagem é atrair para ali (interior) a população, principalmente a estrangeira. As costas do mar e as beiras dos rios são, em todos os países, as mais bem povoadas, pelas facilidades de comunicações que oferecem; ali portanto, se não necessita de incitamento; êste deve dirigir-se ao interior com preferência».

A cr ação, alguns anos mais tarde (1834), de um Municipio Neutro, desnembrado da Provincia Fluminense e destinado a ser a sede do govêrno central, veio arrefecer o entusiasmo dos partidários da mudança para o interior. Um dêles, porém, Francisco Adolfo Varnhagem, Visconde de Pôrto Seguro, permaneceu de pé, lutando pelas suas idéias numa campanha pertinaz que durou quase meio século e pode ser apontada como um dos mais altos exemples de fidelidade de um homem a uma bandeira. Quanto mais sòzinho se via en seu apostolado, mais lhe sentia a grandeza, e maiores reservas de energia encontrava para servi-lo. De 1839 a 1850 sua voz sustentou a idéia que outros haviam abandonado, não permitindo que o silêncio a sepultasse no esquecimento.

Não foì inútil o seu esfôrço, uma vez que a opinião pública se manteve desperta, e, em 1852, Holanda Cavalcanti apresentava ao Senado um projeto de lei, dispondo sôbre a mudança da capital para o interior. Isso, entretanto, não bastava e FRANCISCO AdOLFo VARNHAGEM abalou-se em penosa viagem rumo ao oeste, com o objetivo de realizar pesquisas e observações. Certo de haver encontrado na Vila Formosa da Imperatriz o sítio ideal para a construção da nova capital do Brasil, de lá, em 1877, escreveu a Tomás CoelHo, então Ministro da Agricultura :

«Em todo caso, Exmo. Sr., uma paragem da importância desta única em relaçãr: ao Brasil todo, que pela bondade de seu clina e sua fertilidade, recomendaria no estrangeiro o Brasil todo, que pela sua posição favoreceria notàvelmente o comércio interno de tôdas as provincias, o que (quando viesse a ser a sede do Govêrno) afiançaria nos séculos futuros a segurança e a unidade do império, parece-me que é digna de merccer, desde já, a devida atenção dos podêres públicos do Estado fazendo convergir para ela tôdas as comunicações, começando pela continuação da Estrada Pedro II.»

Treze anos mais tarde, o Decreto $\mathrm{n}^{\circ}$ 914-A, de 1890, ao estabelecer a Constituição Provisória da República dos Estados Unidos do Brasil, inscrevia em seu texto o seguinte dispositivo:

Art. $2 .^{\circ}$. Cada uma das antigas provincias formará um Estado e o antigo municipio neutro constituirá o Distrito Federal, continuando a ser a capital da União, enquanto outra coisa não deliberar o Congresso. 
Parágrafo único. Se o Congresso resolver a mudança da capital, escolhido para êsse fim o tęrritório mediante o consenso do Estado ou Estados de que houver de desmembrar-se, passará o atual Distrito Federal de per si a constituir um Estado.

Criou-se, assim, ambiente para que o problema da mudança da capital do país encontrasse profunda repercussão no seio do Congresso Constituinte, onde foi debatido, em 1891, por Luís Delfino, Nogueira Paranaguá e Virgílio Damásio, êste último caloroso partidário das sugestões que Francisco Adolfo Varnhagem expusera no sell ofício ao ministro Tomás Coelho.

Quem todavia, deù à matéria seu encaminhamento final foi LAuro MüLLER, autor de uma emenda que recebeu a adesão de oitenta e oito constituintes e veio a transformar-se no art. $3^{\circ}$ da Constituição de 1891 assim redigido:

"Fica pertencendo à União, no planalto central da República, uma zona de 14.400 quilômetros quadrados, que será oportunamente demarcada para nela estabelecer-se a futura Capital Federal.»

Embora a vitoriosa emenda de LAuro MüLLER houvesse assentado sua fundamentação no hole histórico cfício de Francisco Adolfo Varnhagem a Tomás Coelho, os constituintes de 1891, com elogiável prudência, limitaram-se a designar uma vasta área do território brasileiro, para que dentro dela, mediante estudos técnicos rigorosos, se delimitasse mais tarde a área da nova capital. Êsses estudos foram confiados à Missão Cruls, cujos membros, em número pouco superior a vinte, foram designados pelo Chefe do Poder Executivo e representavam diferentes ramos da ciência, como a astronomia, a geologia, a botânica, etc. Em aviso de Julho de 1892, o Ministro da Agricultura, Comércio e Obras Públicas estabelecia recomendações destinadas a orientar os trabalhos da Missão Cruls.

Vinte e seis anos mais tarde era encaminhado ao govêrno o relatório da Missão Cruls o qual, alénı de delimitar uma área ( «quadrilátero Cruls》) com seus aspectos físicos fundamentais pormenorizadamente examinados, oferecia suçestões para novos estudos que deveriam ser empreendidos.

Não se podia, pois, dizer ainda que o problema da localização da nova capital tivesse atingido sua sollução definitiva. Mesmo assim, e isso bem demonstra o entusiasmo reinante em tôrno da matéria, o Decreto $n .^{\circ} 4.494$, de 18 de janeiro de 1922, mandava que, como parte dos festejos comemorativos do centenário da independência, fôsse lançada a pedra fundamental da nova cidade no «quadrilátero Cruls» $c$ daterminava as primeiras providências visando à construção de uma estrada de ferro que ligaria os portos do Rio e de Santos ao Planalto Goiano.

Mas, em realidade, nem mesmo a escolha do «quadrilátero Cruls» era coisa firmeinent? estabelecida, tanto assim que a Constituição de 1934 viria mais tarde a dizer (os grifos não são do original) :

«Será transferida a Capital da União para um ponto central do Brasil. O Presidente da República tão logo que esta Constituição. 
entre em vigor, nomeará uma comissão que, sob instruções do Govêrno, procederá a estudos de várias localidades adequadas à instalação da Capital. Concluídos tais estudos serão presentes à Câmara dos Deputados que escolherá o local e tomará, sem perda de tempo, as providências necessárias (Art. 4ํ das Disposições Constitucionais Transitórias).

E porque quanto à localização da nova capital ainda nada houvesse em definitivo, durante a elaboração da carta constitucional de 1946 um considerável grupo de congressistas lançou a idéia da substituição do Planalto Goiano pelo Triângulo Mineiro. Essa idéia que se apoiava em razões muito ponderáveis, foi derrotada pela pequena diferença de seis votos, permanecendo de pé a chamada solução Cruls favorável ao planalto central.

Face ao que determinava o art. $4 .^{\circ}$ do Ato das Disposições Constituciona s Transitórias, então recém promulgado, o Presidente da República nomeou a Comissão de Estudos para Localização da Nova Capital do Brasil, confiando a chefia da mesma ao general Djalma Poli Coelho. O resultado dos trabalhos realizados pela nova comissão foram encaminhados ao Congresso Nacional, conforme determinava o $\S 1^{\circ}$ do citado artigo, a fim de que, 2m lei especial, viesse a ser fixado o prazo para o início da delimitação da área que deveria ser incorporada ao domin'o da União.

Entre agôsto de 1948, quando foi apresentado o relatório da Comissão de Estudos para Localização da Nova Capital do Brasil, e setembro de 1956, quando foi sancionada a Lei 2.874 , várias providências foram tomadas, mereceñdo destaque a instituição da Comissão Especial, presidida pelo genera! Caiado de Castro, e a Comissão de Planejamento da Construção da Mudança da Capital Federal, dirigida pelo Marechal José PessoA.

Completaram-se, com as aludidas providências, os trabalhos demarcatórios a que se referia o $\S 3 .^{\circ}$ do Art. $4 .^{\circ}$ do Ato das Disposições Constituciona:s Transitórias, e pouco depois a Lei 2.874 , de 19 de setembro de 1956, descrevia a linha na qual ficará circunscrito o Distrito Federal, dizendo que ela :

«Começa no ponto da lat. $15^{\circ} 30^{\prime}$ e long. $48^{\circ} 12^{\prime} \mathrm{W}$ Green. Dêsse ponto segue para leste pelo paralelo de $15^{\circ} 30^{\prime} \mathrm{S}$, até encontrar o meridiano $47^{\circ}$ e $25^{\prime} \mathrm{W}$ Green. Dêsse ponto segue o mesmo meridiano de $47^{\circ}$ e $25^{\prime} \mathrm{W}$ Green para o sul até o talvegue do Córrego S. Rita, afluente da margem direita do Rio Prêto. Daí, pelo talvegue do citado córrego S. Rita até a confluência dêste com o Rio Prêto, logo à jusante da Lagoa Feia. Da confluência do córragc. S. Rita com a Fio Prêto, segue pelo talvegue dêste último, na direção sul, até cruzar o paralelo de $16^{\circ} 03^{\prime}$ na direção Oeste, até encontrar o talvegue do R'o Descoberto. Daí para o norte, pelo talvegue do Rio Descoberto, até encontrar o meridiano de $48^{\circ} 12^{\prime}$ W. Green. Daí para o norte pelo meridiano de $48^{\circ}, 12^{\prime} \mathrm{W}$ Green, até encontrar o paralelo de $15^{\circ} 30^{\prime}$, fechando o perimetro». 
Tem-se uma idéia da excelente posição da área escolhida, quando se cbserva que Brasília, dista em quilômetros :

\begin{tabular}{|c|c|}
\hline \\
\hline de Aracaju & 1.270 \\
\hline Belém ........... & 1.575 \\
\hline Belo Horizonte & 725 \\
\hline Boa Vista ........ & 2.490 \\
\hline Cuiabá ........... & 925 \\
\hline uritiba & 1.110 \\
\hline Florianópolis & 1.240 \\
\hline Fortaleza ... & 1.660 \\
\hline oiânia & 125 \\
\hline ão Pessoa & 1.685 \\
\hline capá & 1.770 \\
\hline 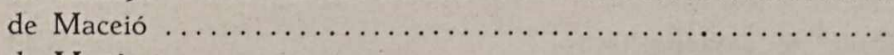 & 1.445 \\
\hline náus & 1.940 \\
\hline ... & 1.750 \\
\hline irto Alegre & 1.650 \\
\hline ôrto Velho & 1.920 \\
\hline ecife..... . & 1.620 \\
\hline io Branco & 2.280 \\
\hline io de Janeiro & 940 \\
\hline alvador $\ldots . .$. . & 1.030 \\
\hline $\begin{array}{l}\text { São Luís } \\
\text { São Paulo }\end{array}$ & $\begin{array}{r}1.495 \\
890\end{array}$ \\
\hline & 1.290 \\
\hline & 940 \\
\hline
\end{tabular}

Para escolha da área de Brasília, a área maior de $50.000 \mathrm{~km}^{2}$, já delimitada no planalto central foi dividida em vinte "unidades" ou "sítios", tomando-se como base para a divisão os dez seguintes fatôres; topografia, textura do solo, drenagem, erosão, água de subsolo, existência de pedras, cobertura vegetal, ocupação pelo homem e usos atuais e potenciais. As vinte unidades estabelecidas de comêço foram, afinal, reduzidas a cinco sítios; o amarelo, próx mo a Leopoldo Bulhões e Vianópolis; o azul, a leste de Anápolis; o verde, a oeste de Planaltina; o vermelho, sobreposto à fronteira entre Goiás e Minas; e o castanho, a $25 \mathrm{~km}$ a sudeste de Planaltina.

Segundo o relatório de Donald J. Belcher \& Associates, emprêsa norteamericana incumbida de promover o levantamento aerofotogramétrico, as investigações de campo, as análises, interpretações e cartas dos $50.000 \mathrm{~km}^{2}$ da grande área do planalto central, os cinco «sitios» finais se equivalem :

«Nenhun é nitidamente superior aos outros em todos os as-pectos. Cada um apresenta determinadas vantagens que lhe são peculiares e que não se repartem igualmente, pelos outros quatro. Qualquer um dêles seria um bom local para a capital do Brasil".

Não convindo dar a preferência por êste ou aquêle sítio o caráter de uma decisão aleatória, adotou-se o critério de confrontar os dados constantes do 
relatório Donald J. Belcher com um coeficiente representado pela soma dos graus atribuíios a cada um dos dez fatôres que deveriam, no caso ser considerados. Tais fatôres, com os respectivos pesos, foram:

1. Clima e salubridade favoráveis $\ldots \ldots \ldots \ldots \ldots \ldots \ldots \ldots . \ldots \ldots$

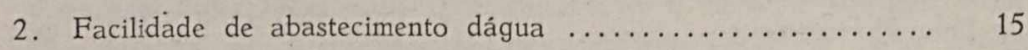

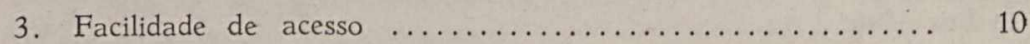

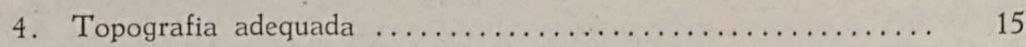

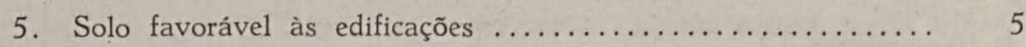

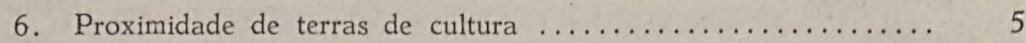

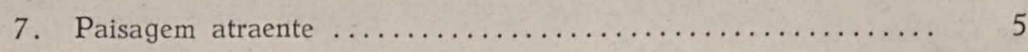

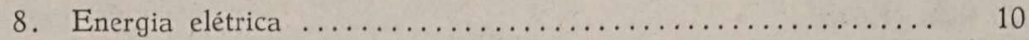

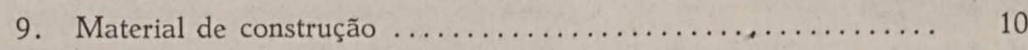

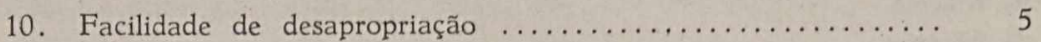

Dos cinco «sitios» foi escolhido, afinal, o Castanho, situado, como já dissemos, a $25 \mathrm{~km}$ a sudeste de Planaltina.

O sítio Castanho é terreno de forma convexa e está integrado numa colina plana, situada entre o Córrego Fundo e o Ribeirão Bananal, a partir do ponto em que um e outro se juntam para formar o Rio Paranoá. Sua elevação é de 1.200 metros, com suave declive para os rios que flanqueiam a colina o que facilita extraordinariamente a circulação e renovação do ar.

O clima, que poda ser classilicedo como su-úmido, varia dentro dos limites de $35^{\circ}$ (máxima absoluta no verão) e $2^{\circ}$ (mínima absoluta no inverno), sendo de $19^{\circ}$ a média no inverno e $22^{\circ}$ a média no verão. Do ponto-de-yista climático, a área na qual está sendo edificada Brasília oferece condições de conforto muito próximas do ideal.

Quanto ao solo, observa-se a predominância de argilas friáveis, de coloração avermelhadì e fácil drenaçem. Sua profundidade é muito variável e a rocha firme que corre sob a capa de argila está situada de modo tal que não constituirá obstáculo à realização de obras subterrâneas. Nas zonas de baixada há afloramentos rochosos de arenito, aptos à produção de agregados e, possivelmente, de pedras para construção civil.

Embora a vegetação seja em geral rasteira, encontram-se dentro da área do sítio, florestas de crescimento secundário, cujo vigor denota a fert́ilidade do solo. Este, se submetido às práticas da agricultura racional, poderá, segundo estudos técnicos já realizados, produzir legumes de quase todos os tipos, batata, milho, arroz trigo, banana, cítricos, mandioca, manga, abacaxi, algodão, café, cana-de-açúcar, figos, azeitonas, caqui, leguminosas, gramí neas forrageiras, etc.

Os manancia s existentes no local são bons e para o aproveitamento de um dêles (Ribeirão Torto) estão sendo realizadas obras de captação de cento e vinte milhões de litros dágua por dia quantidade que se considera bastante para cobrir amplamente as necessidades de Brasilia, ainda quando a cidade houver atingido o áp.ce de seu crescimento demográfico. A posição privi- 
legiada dos aludidos mananciais vai permitir que todos os edifícios da futura capital do país, mesmo os do Congresso Nacional com vinte e oito andares, sejam abastecidos diretamenté até o últ mo andar sem emprêgo de bombas, fato talvez único no mundo.

Brasília será suprida com a energia elétrica proporcionada pelas quedas dágua dos seus arredores. A primeira hidrelétrica, já em final de construção, garantirá, de saída, o aproveitamento de $30.000 \mathrm{HP}$ e dotará a cidade de um soberbo lago de 48 quilômetros de extensão para a prát ca de esportes. Êsse lago, em alguns pontos, terá a largura de 4 quilômetros. 